Original Article

\title{
Handgrip strength dominance is associated with difference in forearm muscle size
}

\author{
Takashi Abe, $\mathrm{PhD}^{1,2)^{*}}$, Jeremy P. Loenneke, $\mathrm{PhD}^{1)}$ \\ 1) Department of Health, Exercise Science, and Recreation Management, Kevser Ermin Applied \\ Physiology Laboratory, School of Applied Sciences, The University of Mississippi, USA \\ 2) Department of Sports and Life Sciences, National Institute of Fitness and Sports in Kanoya: \\ 1 Shiromizu-cho, Kanoya-shi, Kagoshima 891-2393, Japan
}

\begin{abstract}
Purpose] It is unknown whether handgrip strength dominance is related to the size of the forearm flexor muscles. The purpose of the present study was to investigate the relationship between side-by-side differences in handgrip strength and forearm muscle thickness. [Subjects] Thirty-one young women (26 right handed and 5 left handed) between the ages of 20 and 33 years volunteered to participate. [Methods] Two muscle thicknesses (forearm-ulna and forearm-radius muscle thicknesses) were measured using B-mode ultrasound at the anterior forearm on both sides of the body. Handgrip strength was also measured on both sides. [Results] The side-by-side difference in handgrip strength was $10.2 \%$ for the right-handed group, meaning the right hand was stronger. However, the left hand of the left-handed group was $7.8 \%$ stronger compared with their right hand. There was a significant positive correlation between side-by-side differences in handgrip strength and forearm-ulna muscle thickness $(r=0.765)$ and between handgrip strength and forearm-radius muscle thickness $(r=0.622)$. [Conclusion] Our results indicate that side-by-side differences in forearm muscle size may strongly contribute to handgrip strength dominance. Key words: Handgrip strength, B-mode ultrasound, Muscle thickness
\end{abstract}

(This article was submitted Jan. 23, 2015, and was accepted Apr. 3, 2015)

\section{INTRODUCTION}

Handgrip strength (HGS) is an objective measure of muscular function in the upper extremity and has been used as a marker of frailty in older adults ${ }^{1-3)}$. In general, measurement of HGS is performed with the dominant hand to determine the highest strength value. This is because several studies have observed that HGS is $10 \%$ higher with the dominant hand compared with the nondominant hand ${ }^{4,5)}$. In contrast, Petersen et al. $\left.{ }^{6}\right)$ reported that for approximately $20 \%$ of participants (61 of 310 subjects), the HGS of the nondominant hand was equal to or greater than that of the dominant hand; however, the reasons for this phenomenon are unknown.

Recently, a study investigated the relationship between ultrasound-measured forearm muscle thickness (MT) and HGS in old men and women ${ }^{7}$. The authors found that the forearm-ulna MT and forearm-radius MT was significantly correlated with HGS in women. We hypothesized that the HGS dominance may be closely associated with the difference in muscle size in the forearm. Thus, the purpose of this study was to investigate the relationship between side-byside differences in HGS and forearm MT.

*Corresponding author. Takashi Abe (E-mail: t12abe@gmail. com)

C2015 The Society of Physical Therapy Science. Published by IPEC Inc. This is an open-access article distributed under the terms of the Creative Commons Attribution Non-Commercial No Derivatives (by-ncnd) License $<$ http://creativecommons.org/licenses/by-nc-nd/3.0/>.

\section{SUBJECTS AND METHODS}

Thirty-one young women between the ages of 20 and 33 years were recruited from the University of Mississippi campus through a printed advertisement and by word of mouth. All subjects were free of overt chronic disease (e.g., angina, myocardial infarction, arthritic and neuromuscular disorders, etc.) and were not taking any medications known to affect muscle size and function as assessed by self-report. Prior to testing, study approval was granted by the Institutional Review Board of the University of Mississippi, and written informed consent was obtained from all subjects. The study was conducted according to the World Medical Association Declaration of Helsinki.

Hand dominance was ascertained by asking each subject which hand they used to perform well-learned skills such as writing. Twenty-six of the 31 subjects reported right-hand dominancy, while the remaining 5 subjects reported lefthand dominancy. All right-handed subjects used their right hand preferentially for not only writing but also for throwing a ball and grasping a racket. On the other hand, three left-handed subjects used their left hand preferentially for writing, but they used their right mainly for throwing and grasping. Thus, only two left-handed subjects used their left hand preferentially for all activities.

MT was measured using B-mode ultrasound (Aloka SSD-500, Tokyo, Japan) at the anterior forearm [at 30\% proximal between the styloid process and the head of the ulna] on both sides of the body as described previously ${ }^{8)}$. Limb length measurements were taken using anatomical 
Table 1. Forearm girth, handgrip strength and ultrasound-measured forearm muscle thicknesses in young women

\begin{tabular}{lccc}
\hline & Right-hander & Left-hander & Overall \\
\cline { 2 - 4 } & $(\mathrm{n}=26)$ & $(\mathrm{n}=5)$ & $(\mathrm{n}=31)$ \\
\hline Age, yr & $23(3)$ & $22(1)$ & $23(3)$ \\
Height, m & $1.63(0.06)$ & $1.65(0.08)$ & $1.63(0.06)$ \\
Body mass, kg & $63.4(10.4)$ & $68.9(16.0)$ & $64.3(11.3)$ \\
Body mass index, kg/m ${ }^{2}$ & $23.8(3.3)$ & $25.1(3.4)$ & $24.0(3.3)$ \\
Forearm girth (right), cm & $24.2(2.0)^{*}$ & $25.0(3.5)$ & $24.3(2.3)$ \\
Forearm girth (left), cm & $23.6(1.9)$ & $25.1(3.5)$ & $23.8(2.2)$ \\
Muscle thickness, cm & & & \\
Forearm-radius (right) & $1.95(0.22)^{*}$ & $1.94(0.29)$ & $1.95(0.22)$ \\
Forearm-radius (left) & $1.87(0.22)$ & $2.00(0.35)$ & $1.89(0.25)$ \\
Forearm-ulna (right) & $3.51(0.26)^{*}$ & $3.60(0.45)$ & $3.53(0.29)$ \\
Forearm-ulna (left) & $3.34(0.23)$ & $3.70(0.51)$ & $3.40(0.31)$ \\
HGS (right), kg & $26.8(4.2)^{*}$ & $28.0(9.4)$ & $27.0(5.2)$ \\
HGS (left), kg & $24.0(4.3)$ & $29.8(10.6)$ & $24.9(5.9)$ \\
\hline
\end{tabular}

HGS: handgrip strength

*Significant difference from contralateral hand, $\mathrm{p}<0.001$

landmarks. Measurement sites were marked with a marker pen and then limb girth was measured. The measurements for forearm MT were taken while the subjects stood quietly with their elbow extended and relaxed. A linear transducer with a 7.5-MHz scanning head was coated with water-soluble transmission gel to provide acoustic contact and reduce the pressure applied by the scanning head to achieve a clear image. The scanning head was placed on the skin surface at the measurement site using the minimum pressure required, and cross sections of each muscle were imaged. Three images from each site were printed (UP-897MD, Sony, Tokyo, Japan), and mean values of each site were used for data analysis. Two MTs were measured, that is, the perpendicular distances between the subcutaneous adipose tissue-muscle interface and muscle-bone interface of the radius (forearmradius MT) and ulna (forearm-ulna MT), as shown in the study of $\mathrm{Abe}$ et $\mathrm{al}^{7)}$. The distance between two interfaces was measured with a ruler. The precision and linearity of the image reconstruction have been described and confirmed elsewhere ${ }^{9}$. Test-retest reliability of forearm-radius and forearm-ulna MT measurements was determined using the intra-class correlation coefficient $\left(\mathrm{ICC}_{3,1}\right)$, standard error of measurement (SEM), and minimal difference from 11 young subjects ( 5 males and 6 females) scanned twice with a 24 hours interval $(0.928,0.10 \mathrm{~cm}$, and $0.27 \mathrm{~cm}$ and 0.992 , $0.05 \mathrm{~cm}$, and $0.15 \mathrm{~cm}$, respectively).

Handgrip strength was measured using a factory-calibrated hydraulic hand dynamometer (Fabrication Enterprises Inc., Elmsford, NY, USA). All subjects were instructed to maintain an upright standing position to keep their arms at their sides, and to hold the dynamometer in the right hand with the elbow flexed at 90 degrees without squeezing the arm against their body. The size of the dynamometer's handle was set to that which the subjects felt comfortable whilst squeezing the grip. Subjects were allowed to perform one test trial, followed by two maximum trials, and the best value of the trials was used for analysis. Test-retest reli- ability of handgrip strength measurements was previously determined using the $\mathrm{ICC}_{3,1}$, SEM, and minimal difference from the same 11 young subjects described earlier tested twice with an interval of 24 hours $(0.967,2.4 \mathrm{~kg}$ and $6.6 \mathrm{~kg}$, respectively).

Results are expressed as means and standard deviation (SD) for all variables. Side-by-side differences in forearm girth, MT, and HGS were tested using paired student t-test in right-handed $(n=26)$ and left-handed $(n=5)$ groups. Using overall data $(n=31)$, Pearson product correlations were performed to assess the relationship between side-by-side differences (right minus left) in HGS and forearm-ulna MT or forearm-radius MT. Significance was set at $\mathrm{p} \leq 0.05$.

\section{RESULTS}

In the right-handed group, forearm girth, forearm-ulna and forearm-radius MT and HGS were greater $(p<0.001)$ in the right hand than the left hand (Table 1). In the left-handed group, there were no significant $(\mathrm{p}>0.05)$ differences in any of the variables between the two hands. The side-by-side difference in HGS expressed as a percentage was $10.2 \%$ for the right-handed group, meaning the right hand was stronger. However, the left hand in the left-handed group was $7.8 \%$ stronger compared with the right hand.

There was a significant positive correlation between sideby-side differences in HGS and forearm-ulna MT ( $\mathrm{r}=0.765$, $\mathrm{p}<0.001)$ and side-by-side differences in HGS and forearmradius $\mathrm{MT}(\mathrm{r}=0.622, \mathrm{p}<0.001)$.

\section{DISCUSSION}

It is well known that the dominant hand has approximately $10 \%$, on average, greater HGS compared with the nondominant hand. However, it was unknown whether HGS dominance was related to the size of the forearm flexor muscles. To the best of our knowledge, this is the first study that has 
investigated the side-by-side relationship between forearm MT and HGS in young women. Our findings suggest that forearm muscle size may strongly contribute to HGS dominance. The increased muscle size in the dominant hand may occur due to muscle contractions during asymmetric hand motion activities such as carrying a weight with one hand, throwing a ball, or grasping a racket during a sports activity. A previous study investigated the influence of years of work experience on HGS dominance in factory workers with the samples being categorized into five subgroups based on years of employment in factory work ${ }^{10}$. They reported that workers with 0-2 years of experience had a greater side-byside percent difference in HGS compared with workers with 10-20 years of experience, which may be due to their simultaneous use of both hands to complete a task. In addition, our recent studies indicated that forearm MT is correlated with HGS in old women ${ }^{7)}$ and is strongly correlated with HGS in young women ${ }^{11)}$. The regression lines between HGS and MT from the aforementioned study ${ }^{11)}$ revealed that $1 \mathrm{~cm}$ differences in forearm-ulna and forearm-radius MTs are comparable to approximately $13 \mathrm{~kg}$ and $16 \mathrm{~kg}$ differences in HGS, respectively. In the present study, our results support previous studies showing that $1 \mathrm{~cm}$ differences in forearmulna and forearm-radius MTs corresponds to $14.9 \mathrm{~kg}$ and $17.1 \mathrm{~kg}$ differences in HGS, respectively. Therefore, forearm MT is a crucial factor for determining HGS dominance.

Our results showed that the side-by-side difference in HGS was $10.2 \%$ in right-handed women with the right hand being stronger. Although the sample size was very small, the side-by-side difference in HGS was $7.8 \%$ in left-handed women with the left hand being stronger. Petersen et al. ${ }^{6}$ reported that right-handers showed a $12.7 \%$ greater right-hand HGS in young and middle-aged men and women, while there was no difference in HGS $(0.08 \%)$ in left-handers. Cornwell et al. ${ }^{5)}$ reported that right-handers displayed $10.4 \%$ greater right-hand HGS in young and middle-aged adults; the lefthanders exhibited 5.5\% greater left-hand HGS. The results of this study support the $10 \%$ rule for right-handed women.

In conclusion, our results suggest that side-by-side differences in forearm-ulna and forearm-radius MTs were positively correlated with HGS dominance. For young women, forearm muscle size may be a major determinant for evaluating HGS dominance.

\section{ACKNOWLEDGEMENTS}

The authors thank the individuals who participated in this study. We also thank the graduate students of the Department of HESRM at the University of Mississippi, for their help in recruiting subjects. The authors have no conflicts of interest to declare. This study received no specific grant from any funding agency in the public, commercial, or notfor-profit sectors.

\section{REFERENCES}

1) Lauretani F, Russo CR, Bandinelli S, et al.: Age-associated changes in skeletal muscles and their effect on mobility: an operational diagnosis of sarcopenia. J Appl Physiol 1985, 2003, 95: 1851-1860. [Medline] [CrossRef]

2) Taekema DG, Gussekloo J, Maier AB, et al.: Handgrip strength as a predictor of functional, psychological and social health. A prospective population-based study among the oldest old. Age Ageing, 2010, 39: 331-337. [Medline] [CrossRef]

3) Dias FM, Costa SO, Pereira de Freitas J, et al.: Functional capacity of oldest old living in a long-stay institution in Rio De Janeiro, Brazil. J Phys Ther Sci, 2014, 26: 1097-1105. [Medline] [CrossRef]

4) Bechtol CO: Grip test; the use of a dynamometer with adjustable handle spacings. J Bone Joint Surg Am, 1954, 36-A: 820-824, passim. [Medline]

5) Cornwell A, Khodiguian N, Yoo EJ: Relevance of hand dominance to the bilateral deficit phenomenon. Eur J Appl Physiol, 2012, 112: 4163-4172. [Medline] [CrossRef]

6) Petersen P, Petrick M, Connor H, et al.: Grip strength and hand dominance: challenging the 10\% rule. Am J Occup Ther, 1989, 43: 444-447. [Medline] [CrossRef]

7) Abe T, Thiebaud RS, Loenneke JP, et al.: Association between forearm muscle thickness and age-related loss of skeletal muscle mass, handgrip and knee extension strength and walking performance in old men and women: a pilot study. Ultrasound Med Biol, 2014, 40: 2069-2075. [Medline] [CrossRef]

8) Abe T, Kondo M, Kawakami Y, et al.: Prediction equations for body composition of Japanese adults by B-mode ultrasound. Am J Hum Biol, 1994, 6: 161-170. [CrossRef]

9) Abe T, Loenneke JP, Thiebaud RS, et al.: Morphological and functional relationships with ultrasound measured muscle thickness of the upper extremity and trunk. Ultrasound, 2014, 22: 229-235. [CrossRef]

10) Jarjour N, Lathrop JA, Meller TE, et al.: The 10\% rule: grip strength and hand dominance in a factory population. Work, 1997, 8: 83-91. [Medline] [CrossRef]

11) Abe T, Counts BR, Barnett BE, et al.: Associations between handgrip strength and ultrasound-measured muscle thickness in the hand and forearm in young men and women. Ultrasound Med Biol, 2015, 44: 2125-2130. [CrossRef] 